\title{
Body size at birth and age-related macular degeneration in old age
}

\author{
Haapanen, Markus J.
}

2020-08

Haapanen , M J , von Bonsdorff , M B , Fisher , D , Jonasson , F , Eiriksdottir , G , Gudnason , V \& Cotch, M F 2020 , ' Body size at birth and age-related macular degeneration in old age

' , Acta Ophthalmologica , vol. 98 , no. 5 , pp. 455-463 . https://doi.org/10.1111/aos.14340

http://hdl.handle.net/10138/332722

https://doi.org/10.1111/aos. 14340

acceptedVersion

Downloaded from Helda, University of Helsinki institutional repository.

This is an electronic reprint of the original article.

This reprint may differ from the original in pagination and typographic detail.

Please cite the original version. 


\section{Body size at birth and age-related macular degeneration in old age}

Running head: Size at birth and age-related macular degeneration

Markus J. Haapanen ${ }^{1,2}$, Mikaela B. von Bonsdorff ${ }^{2,3}$, Diana Fisher ${ }^{4}$, Fridbert Jonasson ${ }^{5,6}$, Gudny Eiriksdottir $^{5,7}$, Vilmundur Gudnason ${ }^{5,7}$, Mary Frances Cotch ${ }^{4}$

${ }^{1}$ Department of General Practice and Primary Health Care, University of Helsinki and Helsinki University Hospital, Helsinki, Finland

2 Folkhälsan Research Center, Helsinki, Finland

${ }^{3}$ Gerontology Research Center, Faculty of Sport and Health Sciences, University of Jyväskylä, Jyväskylä, Finland

${ }^{4}$ Division of Epidemiology and Clinical Applications, Intramural Research Program, National Eye Institute, National Institutes of Health, Bethesda, Maryland, USA

${ }^{5}$ Faculty of Medicine, University of Iceland, Reykjavik, Iceland

${ }^{6}$ Department of Ophthalmology, Landspitali, The National University Hospital of Iceland, Reykjavik, Iceland

${ }^{7}$ Icelandic Heart Association, Kópavogur, Iceland

Financial support: This work was supported by the National Institutes of Health (Intramural Research Program of the National Institute of Aging and the National Eye Institute, ZIAEY00401), National Institute of Health contract number N01-AG-1-2100, the Icelandic Heart Association, the Icelandic Parliament, the University of Iceland Research Fund and the Helga Jonsdottir and Sigurlidi Kristjansson Research Fund. The sponsor or funding organization had no role in the design or conduct of this research.

Conflict of Interest: no conflicting relationship exists for any author.

For Human Subjects: The study was approved by the Icelandic National Bioethics Committee (VSN 00-063) and by the Institutional Review Board of the U.S. National Institute on Aging, National Institutes of Health. The study was conducted in accordance with the principles of the Declaration of Helsinki. All participants signed an informed written consent.

Word count: 3141.

Corresponding author and reprint requests:

Markus J. Haapanen, BM

Department of General Practice and Primary Health Care

University of Helsinki

PO Box 20

FI-00014 University of Helsinki

markus.haapanen@helsinki.fi 
3

Abstract

Purpose: To study associations between body size at birth and age-related macular degeneration (AMD) in old age.

Methods: The study sample consists of 1497 community-dwelling individuals ( $56.1 \%$ women) aged 67 to 89 years with birth data and retinal data collected twice in old age 5 years apart. Birth data (weight, length, birth order) were extracted from original birth records. Digital retinal photographs were graded to determine AMD status. Data on covariates were collected at the baseline physical examination in old age. Multivariable regression analyses were used to study the association between birth data and AMD adjusting for known confounding factors, including birth year cohort effects.

Results: The prevalence and 5-year incidence of any AMD were $33.1 \%$ and $17.0 \%$, respectively. Men and women born in 1930-1936 were significantly leaner and slightly longer at birth compared to those in earlier birth cohorts. There were no consistent associations between weight, length or ponderal index $(\mathrm{PI})$ at birth and AMD in old age even when stratified by birth cohort. AMD prevalence (39.8\%) and 5-year incidence (28.6\%) were highest in individuals who were in the highest quartile of PI at birth and who were obese in old age.

Conclusion: Body size at birth was not consistently associated with AMD in old age, suggesting that intrauterine growth might have little direct importance in the development of AMD in old age. It is possible that some yet unknown factors related to larger size at birth and obesity in old age may explain differences in the prevalence and incidence of AMD in the aging population. Key words: age-related macular degeneration, body size at birth 


\section{Introduction}

The proportion of individuals aged 60 years and older is projected to double from 12 to $24 \%$ by the year 2050 making it the fastest growing demographic group in developed countries (United Nations, Department of Economic and Social Affairs 2015). Age-related macular degeneration (AMD) is a leading cause of blindness in this population (Mitchell et al. 2018) and the number of people suffering from AMD is projected to increase from 196 million in the year 2020 to 289 million in 2040 (Wong et al. 2014). AMD is a multifactorial condition that involves several risk factors, of which older age, smoking, dietary habits and genetic factors are among the most well-documented (Lambert et al. 2016). In addition, other chronic conditions including cardiovascular disease, hypertension and obesity, have been associated with an increased risk of AMD (Cheung \& Wong 2014). Longitudinal population-based data from the Beaver Dam Eye Study in Wisconsin has suggested that a birth cohort effect may influence the prevalence of AMD (Huang et al. 2003). However, relatively little is known about possible associations among early life factors from conception through gestation that influence health and morbidity throughout life, including signs of AMD in old age.

The Developmental Origins of Health and Disease (DOHaD) hypothesis highlights the importance of exposures that occur during critical phases of development and the long-lasting effects they may have on later health (Barker 1995, Barker 1998). Evidence from meta-analyses of epidemiological studies stress developmental influences in susceptibility to clinical risk factors associated with AMD (Cheung \& Wong 2014), importantly cardiovascular disease (Wang et al. 2014) and hypertension (Zhang et al. 2013), as the result of poor growth indicated by small size at birth, as opposed to obesity (Yu et al. 2011), resulting from accelerated growth and large size at birth. 
The retina undergoes rapid development during early gestation and continues to mature postpartum (Hendrickson 2016). Facing undernutrition in utero, organisms prioritize growth of vital tissues including the brain at the expense of others, resulting in smaller size at birth. Low birth weight has been associated with altered ocular dimensions in children (Li et al. 2014) and adults (Fieß et al. 2019). To our knowledge, there are 3 earlier cross-sectional studies reporting on the association between body size at birth and AMD, which show inconsistent results. In a multiethnic study from the United States, higher self-reported birth weight was associated with early AMD, assessed in 1993-1995 in a White population ( $n=4083$, mean age 60 years, 208 AMD cases) but not in the study population as a whole (Liew et al. 2008). Findings from a UK population consisting of White participants found evidence of an association between higher birth weight and head circumference-to-birth weight and early or late AMD among 380 individuals aged 66 to 75 years (Hall et al. 2002). However, null findings were reported by another study from Hertfordshire, UK, which included 717 participants of similar age (Sayer et al. 1998). Using longitudinal data from a subset of participants from the Age, Gene/Environment Susceptibility-Reykjavik (AGES) study on whom birth data were available, we investigated associations between body size at birth and both prevalent and incident AMD in old age. 


\section{Materials and methods}

\section{Study population}

The AGES study (Harris et al. 2007) is a population-based cohort study comprising 5764 participants who were randomly selected from survivors $(n=11,549)$ of the Reykjavik Study (Sigurdsson et al. 1993). Clinical assessment for AMD was first performed among 5272 participants at a study visit (AGES-I) during 2002-2006 (Jonasson et al. 2011). Of these, 2868 survivors provided information on AMD at a 5-year follow up visit (AGES-II) during 2007-2011 (Jonasson et al. 2014). Original midwives' birth records for 1696 AGES participants were available for this analysis (Birgisdottir et al. 2002). Data on body size at birth, AMD and covariates were available for 1497 participants whose mean age was 75.2 years at the baseline AGES-I examination. The study was approved by the Icelandic National Bioethics Committee (VSN 00-063) and by the Institutional Review Board of the U.S. National Institute on Aging, National Institutes of Health. The study was conducted in accordance with the principles of the Declaration of Helsinki. All participants signed an informed written consent.

\section{Birth data}

Birth data were extracted from birth records obtained from the National Archives of Iceland (Gunnarsdottir et al. 2002). Birth weight was recorded to the nearest $50 \mathrm{~g}$ and length in centimeters from crown to heel. Ponderal index $(\mathrm{PI})$ was calculated as $\left[\mathrm{kg} / \mathrm{m}^{3}\right]$. Birth order was grouped into first, second, third and fourth or later born. The average body size of the survivors of the Reykjavik Study $(n=4828)$ was similar to that of participants included in the present study (Birgisdottir et al. 2002). Information on gestational age was not available but at that time a newborn was considered preterm if they were less than $48 \mathrm{~cm}$ long at birth (Gunnarsdottir et al. 2002). By this definition, 
there were 18 preterm births in this sample. Exclusion of preterm births $(n=18)$ from the analyses did not change the results.

\section{Age-Related Macular Degeneration}

Fundus photography was performed using a standardized protocol as described in detail elsewhere (Jonasson et al. 2011). In brief, using a Canon CR6 nonmydriatic camera with a Canon D60 camera back, two 45-degree digital retinal images, one centered on the optic nerve and the other on the macula, were taken through the pharmacologically dilated pupil of each eye. The retinal images were evaluated by masked graders at the University of Wisconsin Ocular Epidemiology Reading Center for assessment of AMD in a semiquantitative fashion. EyeQ Lite image processing software was used with a standard AMD grading protocol including the modified Wisconsin Age-Related Maculopathy Grading System (Jonasson et al. 2011, Klein et al. 1991, Klein et al. 2006). Early AMD was defined as having any soft drusen and pigmentary abnormalities or the presence of large soft drusen $\geq 125 \mu \mathrm{m}$ in diameter with a large drusen area (>500 $\mu \mathrm{m}$ diameter circle) or large $(\geq 125 \mu \mathrm{m}$ in diameter) soft distinct drusen in the absence of late AMD. Any AMD included early AMD and late AMD, defined as presence of at least one of the following: geographical atrophy or exudative AMD (pigmental epithelial detachment, subretinal hemorrhage, visible subretinal new vessel, subretinal fibrous scar or later laser treatment scar for AMD). Inter and intraobserver agreement on the AMD classification was found to be excellent (Jonasson et al. 2011).

\section{Covariates}

The participants were categorized into 3 distinct geo-economic birth cohorts according to their year of birth: 1914 to 1924 (24.5\% of the participants), 1925 to 1929 (32.2\%) and 1930 to 1936 (43.3\%).

Data on covariates from old age were collected at the first AGES clinical examination. Smoking 
151

history was grouped into never smokers, ex-smokers and current smokers. Educational attainment was dichotomized as having primary or secondary education and college or university education. Body mass index (BMI) was calculated as weight divided by height squared $\left[\mathrm{kg} / \mathrm{m}^{2}\right]$. Coronary heart disease was defined as having documented hospital reports of a myocardial infarction, angioplasty, or coronary artery bypass surgery. Diabetes was defined as having a history of diabetes, use of glucose-modifying medication or $\mathrm{HbA} 1 \mathrm{c}$ level $\geq 6.5 \%$. Total cholesterol and high-density lipoprotein cholesterol (HDL) were measured in the IHA laboratory from blood samples using standard methods. Information on Complement Factor H (CFH) polymorphism (rs1061170), genotyped by Illuminia Genotyping Services, San Diego, California, was available for a subset of individuals who participated in a candidate gene SNP array.

\section{Statistical Methods}

For comparing characteristics of the study population, Pearson's $\chi 2$-test was used for categorical variables and analysis of variance for continuous variables. Since body size at birth varied by birth cohort and sex, results were stratified by birth cohort and sex. Due to differences for birth weights and lengths, which were polarized further between men and women within cohorts, the focus of subsequent analyses was the summary measure ponderal index. The association between body size at birth and $A M D$ in old age was investigated with multiple logistic regression models. Ponderal index was categorized into three groups representing low (lowest quartile), normal ( $25^{\text {th }}$ to $75^{\text {th }}$ percentile) and high (highest quartile) ponderal index, with cut-offs at 24.0 and $28.0 \mathrm{~kg} / \mathrm{m}^{3}$, respectively. In old age, the participants were classified as either normal weight $\left(\mathrm{BMI}<25 \mathrm{~kg} / \mathrm{m}^{2}\right)$, overweight (BMI $25.0-30.0 \mathrm{~kg} / \mathrm{m}^{2}$ ) or obese $\left(\mathrm{BMI}>30 \mathrm{~kg} / \mathrm{m}^{2}\right)$. The analyses were first adjusted for birth cohort (if not stratified) and then subsequently for the old age variables: educational attainment, body mass index, smoking status, alcohol consumption, coronary heart disease and 
175 diabetes, total cholesterol, and HDL cholesterol. Birth order was not associated with AMD and was

176 not included in the regression models. CFH was also not included due to its limited availability in the 177 sample. Two-tailed analyses, assuming a 95\% confidence level, were completed using SAS version 1789.4 (SAS Institute, Cary, NC, USA). 


\section{Results}

At the mean age of 75.2 years (SD 4.9, range 66 to 89 years), 391 (26.1\%) participants had early and 105 (7.0\%) participants had late AMD. Of those who did not have AMD at the first visit, 123 (17.0\%) developed early or late AMD by the 5-year follow-up visit. Characteristics of the men and women according to birth cohort are presented in Table 1. The proportion of never smokers was highest (43.7\%) in the oldest cohort and lowest (33.9\%) in the youngest cohort and consistently higher among women than men. The prevalence of coronary heart disease and diabetes increased with older age and were higher among men than women. Among those with birth data, the availability of AMD data by mortality is presented in the Supplementary Table.

In Table 1, the youngest cohort weighed less and was leaner at birth than the two older cohorts. Mean birth weight was less [3669 g (SD 509)] for the youngest cohort born 1930-36 than for the oldest cohort born 1914-24 [3792 g (SD 568)], which was also true for ponderal index, $24.9 \mathrm{~kg} / \mathrm{m}^{3}$ (SD 2.7 ) and $26.7 \mathrm{~kg} / \mathrm{m}^{3}$ (SD 3.7), respectively. In contrast, mean length at birth was slightly longer for the youngest cohort compared to the older two cohorts. Ponderal index varied slightly by AMD status in the three birth cohort groups (Table 2). Mean ponderal index was higher among individuals with missing AMD data at AGES-II ( $n=580)$ than among those with AMD data at AGES-II $(n=917), 26.3$ $\mathrm{kg} / \mathrm{m}^{3}, \mathrm{SD} 3.4$ vs. $25.6 \mathrm{~kg} / \mathrm{m}^{3}, \mathrm{SD} 3.2$; unadjusted $\mathrm{p}<0.01$, but the difference became non-significant after adjusting for age (age-adjusted $p=0.47$, data not shown).

There was no consistent or obvious relationship between AMD, PI and obesity. The prevalence (39.8\%) and 5-year incidence (28.6\%) of AMD were highest among individuals who belonged to the highest PI group at birth and who were obese in old age (Figure 1). In contrast, the prevalence of AMD was lowest (28.0\%) among individuals in the lowest PI group at birth and medium group of 
body weight in old age. The lowest 5-year incidence of AMD (12.8\%) was observed for those in the medium PI group at birth and normal body weight in old age.

No associations between body size at birth and prevalent AMD (examined at AGES-I and/or AGESII) were observed in analyses with data from women and men combined (data not shown) or when stratified by birth cohort (Table 3). When the AGES analytic sample was restricted to the birth years matching each of the other three published studies (Figure 2), the results were unchanged (data not shown). When the analysis was restricted to the first cross-sectional AMD measurement (examined at AGES-I), higher birth weight and ponderal index protected from prevalent AMD in 201 men born 1925-29: 1-unit increases in birth weight $(\mathrm{kg})$ and ponderal index $\left(\mathrm{kg} / \mathrm{m}^{3}\right)$ were associated with a decreased odds of $A M D$, odds ratio (OR) $0.64(95 \% \mathrm{Cl} 0.43,0.96)$ and $\mathrm{OR} 0.58(95 \% \mathrm{Cl} 0.38,0.90)$, for birth weight and ponderal index, respectively, adjusting for age, education, BMI, smoking, alcohol consumption, prevalent coronary heart disease and diabetes (data not shown). No associations were observed among women or in men belonging to the other two birth cohort strata (data not shown).

When the three birth cohorts were pooled at AGES-I examination, a 1-unit increase in ponderal index was associated with a reduced OR of AMD among men (OR $0.79,95 \% \mathrm{Cl} 0.64$ to 0.97 ) but with increased OR of $A M D$ among women (OR 1.19, $95 \% \mathrm{Cl} 1.00$ to 1.41), adjusting for birth cohort (data not shown). The association was little changed after further adjustment for covariates in men (OR $0.78,95 \% \mathrm{Cl} 0.63$ to 0.97 ) but became non-significant in women (OR 1.14, $95 \% \mathrm{Cl} 0.96,1.36$; data not shown). 
226 Data on body size at birth and incident AMD is presented in Table 4 stratified by birth cohort. A 1-

227 unit increase in birth weight $(\mathrm{kg})$ was associated with an increased risk of incident AMD in those 228 born 1925-29 whereas a 1-unit increase in ponderal index $\left(\mathrm{kg} / \mathrm{m}^{3}\right)$ was associated with a decreased 229 risk of incident AMD in those born 1914-24. 


\section{Discussion}

Evidence from epidemiological studies stress the importance of developmental influences, particularly poor growth in utero, in susceptibility to chronic diseases (Wang et al. 2014, Zhang et al. 2013), of which several have been suggested to be concomitant risk factors for AMD (Cheung \& Wong 2014). We found that body size at birth, which is a crude marker of intrauterine growth, was not consistently associated with AMD in old age.

Evidence of an association between body size at birth and AMD suggest that a high birth weight may confer a modest risk of AMD in a White population, as was shown in some (Hall et al. 2002, Liew et al. 2008) but not all (Sayer et al. 1998) previous reports. The present study extends previous observations to those aged 80 years and older, and to our knowledge, is the first to study the relationship between body size at birth and incident AMD. Icelanders have one of the highest mean birth weights in the World (Atladottir \& Thorsdottir 2000). High rates of longevity in this population combined with its high rate of AMD, considerably higher than in other cohorts of comparable age (Jonasson et al. 2011), make this cohort uniquely suited to investigate an association between AMD and birth size. Although higher BMI in old age was previously found to be associated with incident AMD in AGES data (Jonasson et al. 2014), we found no evidence to support any trend between body size at birth and prevalent or 5-year incident AMD in this population of 1497 Icelanders aged 65 years and older. Some associations between birth data and AMD were observed in the present study, however, they were inconsistent and disappeared after stratification by birth cohort and sex.

The mechanisms underlying the plausible association between accelerated intrauterine growth, reflected in high birth weight, and $A M D$, are not known. In the present study, we found that both the prevalence and 5-year incidence of AMD were highest in individuals who belonged to the highest 
254

group of ponderal index at birth and who were obese in old age. Rather than resulting directly from accelerated intrauterine growth, it is possible that a risk of AMD could be linked with metabolic programming of one of its risk factors, namely obesity, which has consistently been associated with higher birth weight (Yu et al. 2011). The authors of one study (Hall et al. 2002) proposed that individuals with AMD had disproportionately smaller head circumference to birth weight, possibly indicating that a pattern of retarded growth of structures in the brain, would be linked with AMD. However, we were not able to study that relationship in the present study due to lack of data on head circumference.

Overall, while greater weight at birth has been associated with obesity (Yu et al. 2011), associations between small body size at birth, namely low birth weight, and aging-related chronic diseases (Harder et al. 2007, Wang et al. 2014, Zhang et al. 2013), geriatric syndromes including frailty (Haapanen et al. 2018) and measures of the aging process such as bone mass and muscle strength (Hanson et al. 2016), support a greater role of non-optimal intrauterine growth in the pathogenesis of aging-related chronic disease. This notion is supported by recent findings (Fieß et al. 2019) on eye development where a low birth weight was associated with a steeper corneal curvature, smaller corneal diameter, and thinner central cornea, in individuals aged 40-80 years, suggesting a potential role of intrauterine growth in anatomical alterations of the eye.

A major strength of the present study is that it involved a relatively large sample of older persons with approximately 500 prevalent or incident cases of $A M D$, representing one third of the entire study population. Information on body size at birth was extracted from actual birth records and standardized fundus images were graded at the University of Wisconsin reading center for AMD. Information on gestational age and head circumference was not available, which limited our ability 
in differentiating between prematurity and growth retardation in infants born at term in this cohort. Mortality and loss to follow-up may have resulted in selective survival of healthier participants as well as participants with possibly higher mean birth weights. However, mean body size at birth of the AGES participants without AMD data was similar to that of participants with AMD data who were included in the present study. While stratifying by birth cohort enabled us to minimize confounding due to chronological age, it also allowed us to consider, in a general sense, geoeconomic conditions indicative of Icelandic life at the time. Accordingly, body size at birth varied between the three birth cohorts. Those in the youngest cohort, born during the Great Depression in Reykjavik, Iceland, as illustrated in Figure 2, were consequently smaller in size at birth whereas those born between 1925 and 1929 were heavier at birth but gained less weight growing up during the Depression (Imai et al. 2012). Consistent with birth cohort effects reported for prevalent (Huang et al. 2003) and incident AMD from a US cohort (Klein et al. 2008), our results corroborate birth cohort effects in an Icelandic cohort, although generalizability to other populations, or other ethnicities, may be limited since both cohorts included only Caucasians. Additionally, findings from this older Icelandic cohort may differ from subsequent generations of Icelanders of comparable age who were born after global travel became routine and the nation's standard of living improved dramatically.

In conclusion, body size at birth was not consistently associated with AMD in this White population characterized by high birth weight, longevity and higher than average rates of AMD. Therefore, prenatal exposures are likely to have little direct or independent effects on the development of AMD in old age. Indirect effects on AMD, however, may be mediated through other unmeasured factors that influence body size at birth and/or obesity in old age. It is possible that prevention of obesity during the life course may also reduce the prevalence and incidence of AMD in old age. 


\section{References}

Atladottir H \& Thorsdottir I (2000): Energy intake and growth of infants in Iceland-a population with high frequency of breast-feeding and high birth weight. Eur J Clin Nutr 54: 695-701.

Barker DJP (1995): Fetal origins of coronary heart disease. BMJ 311: 171-174.

Barker DJP (1998): Mothers, babies and health in later life (2nd ed.). Edinburgh: Churchill Livingstone.

Birgisdottir BE, Gunnarsdottir I, Thorsdottir I, Gudnason V \& Benediktsson R (2002): Size at birth and glucose intolerance in a relatively genetically homogeneous, high-birth weight population. Am J Clin Nutr 76: 399-403.

Cheung CMG \& Wong TY (2014): Is age-related macular degeneration a manifestation of systemic disease? New prospects for early intervention and treatment. J Intern Med 276: 140-153.

Fieß A, Schuster AK, Nickels S, et al. (2019): Association of Low Birth Weight With Altered Corneal Geometry and Axial Length in Adulthood in the German Gutenberg Health Study. JAMA Ophthalmol.

Gunnarsdottir I, Birgisdottir BE, Benediktsson R, Gudnason V \& Thorsdottir I (2002): Relationship between size at birth and hypertension in a genetically homogeneous population of high birth weight. J Hypertens 20: 623-8.

Haapanen MJ, Perälä MM, Salonen MK, Kajantie E, Simonen M, Pohjolainen P, Eriksson JG \& von Bonsdorff MB (2018): Early life determinants of frailty in old age: the Helsinki Birth Cohort Study. Age Ageing 47: 569-575.

Hall NF, Gale CR, Syddall H, Martyn CN \& Phillips DIW (2002): Relation between size at birth and risk of age-related macular degeneration. Invest Ophthalmol Vis Sci 43: 3641-5.

Hanson MA, Cooper C, Aihie Sayer A, Eendebak RJ, Clough GF \& Beard JR (2016): Developmental aspects of a life course approach to healthy ageing. J Physiol 594: 2147-2160. 
Harder T, Rodekamp E, Schellong K, Dudenhausen JW \& Plagemann A (2007): Birth Weight and Subsequent Risk of Type 2 Diabetes: A Meta-Analysis. Am J Epidemiol 165: 849-857.

Harris TB, Launer LJ, Eiriksdottir G, et al. (2007): Age, Gene/Environment Susceptibility-Reykjavik Study: multidisciplinary applied phenomics. Am J Epidemiol 165: 1076-87.

Hendrickson A (2016): Development of Retinal Layers in Prenatal Human Retina. Am J Ophthalmol 161: 29-35.e1.

Huang GH, Klein R, Klein BEK \& Tomany SC (2003): Birth cohort effect on prevalence of age-related maculopathy in the Beaver Dam Eye Study. Am J Epidemiol 157: 721-729.

Imai CM, Halldorsson TI, Gunnarsdottir I, Gudnason V, Aspelund T, Jonsson G, Birgisdottir BE \& Thorsdottir I (2012): Effect of birth year on birth weight and obesity in adulthood: comparison between subjects born prior to and during the great depression in Iceland. (Wang G, Ed.)PLoS One 7: e44551.

Jonasson F, Arnarsson A, Eiríksdottir G, et al. (2011): Prevalence of Age-related Macular Degeneration in Old Persons: Age, Gene/Environment Susceptibility Reykjavik Study. Ophthalmology 118: 825-830.

Jonasson F, Fisher DE, Eiriksdottir G, et al. (2014): Five-year incidence, progression, and risk factors for age-related macular degeneration: the age, gene/environment susceptibility study. Ophthalmology 121: 1766-72.

Klein R, Davis MD, Magli YL, Segal P, Klein BE \& Hubbard L (1991): The Wisconsin age-related maculopathy grading system. Ophthalmology 98: 1128-34.

Klein R, Klein BEK, Knudtson MD, et al. (2006): Prevalence of age-related macular degeneration in $4 \mathrm{racial} / \mathrm{ethnic}$ groups in the multi-ethnic study of atherosclerosis. Ophthalmology 113: 37380.

Klein R, Knudtson MD, Lee KE, Gangnon RE \& Klein BEK (2008): Age-Period-Cohort Effect on the 
Lambert NG, ElShelmani H, Singh MK, et al. (2016): Risk factors and biomarkers of age-related macular degeneration. Prog Retin Eye Res 54: 64-102.

Li XQ, Munkholm A, Copenhagen Child Cohort 2000 Study Group M, Larsen M \& Munch IC (2014):

Sayer AA, Cooper C, Evans JR, Rauf A, Wormald RP, Osmond C \& Barker DJ (1998): Are rates of ageing determined in utero? Age Ageing 27: 579-83.

Sigurdsson E, Thorgeirsson G, Sigvaldason H \& Sigfusson N (1993): Prevalence of coronary heart disease in Icelandic men 1968-1986. The Reykjavik Study. Eur Heart J 14: 584-91.

United Nations, Department of Economic and Social Affairs PD (2015): World Population Prospects: The 2015 Revision, Key Findings and Advance Tables. Working Paper No. ESA/P/WP.241. New York.

Wang S-F, Shu L, Sheng J, Mu M, Wang S, Tao X-Y, Xu S-J \& Tao F-B (2014): Birth weight and risk of coronary heart disease in adults: a meta-analysis of prospective cohort studies. J Dev Orig Health Dis 5: 408-419.

Wong WL, Su X, Li X, Cheung CMG, Klein R, Cheng C-Y \& Wong TY (2014): Global prevalence of agerelated macular degeneration and disease burden projection for 2020 and 2040: a systematic review and meta-analysis. Lancet Glob Heal 2: e106-e116. 
374 Yu ZB, Han SP, Zhu GZ, Zhu C, Wang XJ, Cao XG \& Guo XR (2011): Birth weight and subsequent risk 375 of obesity: a systematic review and meta-analysis. Obes Rev 12: 525-542.

376 Zhang Y, Li H, Liu S, Fu G, Zhao Y, Xie Y-J, Zhang Y \& Wang Y (2013): The associations of high birth 377 weight with blood pressure and hypertension in later life: a systematic review and meta$378 \quad$ analysis. Hypertens Res 36: 725-735.

379 


\begin{tabular}{|c|c|c|c|c|c|c|c|c|c|c|c|c|}
\hline & \multicolumn{4}{|c|}{ All Individuals ( $N=1497$ ) } & \multicolumn{4}{|c|}{ Men $(\mathrm{N}=657)$} & \multicolumn{4}{|c|}{ Women $(\mathrm{N}=840)$} \\
\hline & $\begin{array}{c}1914-1924 \\
(24.5 \%, N=367)\end{array}$ & $\begin{array}{c}1925-1929 \\
(32.2 \%, \mathrm{~N}=482)\end{array}$ & $\begin{array}{c}1930-1936 \\
(43.3 \%, N=648)\end{array}$ & $\begin{array}{c}\text { p- } \\
\text { value* }\end{array}$ & $\begin{array}{c}1914-1924 \\
(25.9 \%, \mathrm{~N}=170)\end{array}$ & $\begin{array}{c}1925-1929 \\
(30.6 \%, \mathrm{~N}=201)\end{array}$ & $\begin{array}{c}1930-1936 \\
(43.5 \% \mathrm{~N}=286)\end{array}$ & $\begin{array}{c}\text { p- } \\
\text { value* }\end{array}$ & $\begin{array}{c}1914-1924 \\
(23.5 \%, N=197)\end{array}$ & $\begin{array}{c}1925-1929 \\
(33.5 \%, N=281)\end{array}$ & $\begin{array}{c}1930-1936 \\
(43.1 \%, N=362)\end{array}$ & $\begin{array}{c}p- \\
\text { value }\end{array}$ \\
\hline \multicolumn{13}{|l|}{ Birth Data } \\
\hline Birth Weight, grams & $3792(568)$ & $3790(561)$ & 3669 (509) & 0.02 & $3888(553)$ & 3915 (607) & $3729(527)$ & 0.06 & 3709 (569) & $3700(508)$ & 3621 (489) & 0.12 \\
\hline Birth Length, $\mathrm{cm}$ & $52.2(2.4)$ & $52.2(2.5)$ & $52.8(2.4)$ & 0.03 & $52.7(2.5)$ & $52.7(2.4)$ & $53.2(2.3)$ & 0.30 & $51.8(2.3)$ & $51.9(2.4)$ & $52.5(2.4)$ & 0.07 \\
\hline Ponderal Index & $26.7(3.7)$ & $26.6(3.4)$ & $24.9(2.7)$ & $<0.01$ & $26.7(3.7)$ & $26.8(3.5)$ & $24.8(2.7)$ & $<0.01$ & $26.6(3.7)$ & $26.5(3.3)$ & $25.0(2.7)$ & $<0.01$ \\
\hline Birth Order & & & & $<0.01$ & & & & $<0.01$ & & & & 0.27 \\
\hline First & $21.6(79)$ & $25.1(121)$ & $37.3(241)$ & & $20.6(35)$ & $20.4(41)$ & $37.8(108)$ & & $12.0(44)$ & $28.5(80)$ & $36.9(133)$ & \\
\hline Second & $25.4(93)$ & $22.0(106)$ & $25.4(164)$ & & $26.5(45)$ & $22.9(46)$ & $25.5(73)$ & & $24.5(48)$ & $21.4(60)$ & $25.3(91)$ & \\
\hline Third & $16.9(62)$ & $17.8(86)$ & $15.0(97)$ & & $19.4(33)$ & $17.9(36)$ & $15.0(43)$ & & $14.8(29)$ & $17.8(50)$ & $15.0(54)$ & \\
\hline Fourth $(+)$ & $36.1(132)$ & $35.1(169)$ & $22.3(144)$ & & $33.5(57)$ & $38.8(78)$ & $21.7(62)$ & & $38.3(75)$ & $32.4(91)$ & $22.8(82)$ & \\
\hline \multicolumn{13}{|l|}{ Midlife Data } \\
\hline Body Mass Index & $25.9(3.8)$ & $25.0(3.3)$ & $25.2(3.6)$ & 0.04 & $26.2(3.4)$ & $25.3(3.1)$ & $25.8(3.5)$ & 0.33 & $25.6(4.1)$ & $24.8(3.5)$ & $24.7(3.7)$ & 0.15 \\
\hline Systolic Blood Pressure & $137.6(17.8)$ & $132.8(17.3)$ & $128.9(15.3)$ & 0.37 & $138.9(19.0)$ & $137.8(16.7)$ & $134.4(14.7)$ & 0.58 & $136.5(16.7)$ & $129.2(16.8)$ & $124.6(14.3)$ & 0.73 \\
\hline Diastolic Blood Pressure & $86.4(10.2)$ & $83.9(10.0)$ & $82.0(9.5)$ & 0.21 & $88.9(11.2)$ & $87.9(10.3)$ & $86.4(9.3)$ & 0.65 & $84.2(8.7)$ & $81.1(8.8)$ & $78.5(8.1)$ & 0.08 \\
\hline \multicolumn{13}{|l|}{ Old Age Data } \\
\hline Age & $82.0(2.3)$ & $75.9(1.7)$ & $70.8(2.1)$ & $<0.01$ & $82.1(2.5)$ & $76.1(1.6)$ & $71.2(1.9)$ & $<0.01$ & $81.9(2.1)$ & $75.8(1.8)$ & $70.4(2.3)$ & $<0.01$ \\
\hline Body Mass Index & $27.0(4.4)$ & $27.1(4.3)$ & $27.9(4.7)$ & 0.40 & $26.8(3.6)$ & $26.8(3.7)$ & $28.0(4.1)$ & 0.05 & $27.2(5.0)$ & $27.4(4.7)$ & $27.9(5.1)$ & 0.48 \\
\hline $\begin{array}{l}\text { Education, Completed Secondary } \\
\text { or More }\end{array}$ & $78.5(285)$ & $78.2(376)$ & $85.3(551)$ & 0.14 & $83.8(140)$ & $90.0(180)$ & $89.9(256)$ & 0.32 & $74.0(145)$ & $69.8(196)$ & $81.7(295)$ & 0.37 \\
\hline Never Smoked & $43.7(160)$ & $42.7(206)$ & $33.9(219)$ & 0.74 & $33.7(57)$ & $29.9(60)$ & $24.2(69)$ & 0.27 & $52.3(103)$ & $52.0(146)$ & $41.6(150)$ & 0.12 \\
\hline $\begin{array}{l}\text { Alcohol Consumption, } \\
\text { One or More Grams Per Week }\end{array}$ & $65.9(241)$ & $69.3(332)$ & $75.0(484)$ & $<0.01$ & $69.8(118)$ & 73.5 (147) & $80.7(230)$ & 0.22 & $62.4(123)$ & $66.3(185)$ & $70.6(254$ & 0.02 \\
\hline Coronary Heart Disease & $25.3(93)$ & $20.3(98)$ & $18.1(117)$ & 0.01 & $34.7(59)$ & $29.4(59)$ & $26.6(76)$ & 0.12 & $17.3(34)$ & $13.9(39)$ & $11.3(41)$ & 0.04 \\
\hline Diabetes & $14.7(54)$ & $11.6(56)$ & $7.7(50)$ & $<0.01$ & $18.2(31)$ & $12.9(26)$ & $9.8(28)$ & 0.04 & $11.7(23)$ & $10.7(30)$ & $6.1(22)$ & $<0.01$ \\
\hline Total Cholesterol, $\mathrm{mmol} / \mathrm{l}$ & $5.6(1.2)$ & $5.7(1.2)$ & $5.7(1.0)$ & 0.01 & $5.1(1.1)$ & $5.2(1.1)$ & $5.3(1.0)$ & 0.15 & $6.0(1.2)$ & $6.0(1.1)$ & $5.9(1.0)$ & $<0.01$ \\
\hline $\begin{array}{l}\text { High-Density Lipoprotein } \\
\text { Cholesterol, mmol/l }\end{array}$ & $1.6(0.5)$ & $1.6(0.5)$ & $1.6(0.5)$ & 0.61 & $1.5(0.4)$ & $1.5(0.5)$ & $1.4(0.4)$ & 0.14 & $1.8(0.5)$ & $1.7(0.4)$ & $1.7(0.5)$ & 0.33 \\
\hline CFH Genotype rs1061170** & & & & 0.07 & & & & 0.04 & & & & 0.30 \\
\hline Allele TT & $27.0(44)$ & $39.4(84)$ & $39.3(88)$ & & $33.8(25)$ & $38.5(30)$ & $41.4(41)$ & & $21.4(19)$ & $40.0(54)$ & $37.6(47)$ & \\
\hline TC & $54.0(88)$ & $46.0(98)$ & $45.5(102)$ & & $52.7(39)$ & $50.0(39)$ & $45.5(45)$ & & $55.1(49)$ & $43.7(59)$ & $45.6(57)$ & \\
\hline CC & $19.0(31)$ & $14.6(31)$ & $15.2(34)$ & & $13.5(10)$ & $11.5(9)$ & $13.1(13)$ & & $23.6(21)$ & $16.3(22)$ & $16.8(21)$ & \\
\hline \multicolumn{13}{|l|}{ AMD Status } \\
\hline AMD at AGES-I & & & & 0.32 & & & & 0.27 & & & & 0.85 \\
\hline None & $57.8(212)$ & $75.1(362)$ & $84.9(550)$ & & $61.2(104)$ & $79.6(160)$ & $85.7(245)$ & & $54.8(108)$ & $71.9(202)$ & $84.3(305)$ & \\
\hline Any AMD & $42.2(155)$ & $24.9(120)$ & $15.1(98)$ & & $38.8(66)$ & $20.4(41)$ & $14.3(41)$ & & $45.2(89)$ & $28.1(79)$ & $15.8(57)$ & \\
\hline Early AMD & $32.2(118)$ & $22.0(106)$ & $12.7(82)$ & & $30.0(51)$ & $18.4(37)$ & $12.9(37)$ & & $34.0(67)$ & $24.6(69)$ & $12.4(45)$ & \\
\hline Late AMD & $10.1(37)$ & $2.9(14)$ & $2.5(16)$ & & $8.8(15)$ & $2.0(4)$ & $1.4(4)$ & & $11.2(22)$ & $3.6(10)$ & $3.3(12)$ & \\
\hline Prevalent AMD at AGES-I or II & & & & 0.21 & & & & 0.09 & & & & 0.83 \\
\hline None & $49.6(182)$ & $67.4(325)$ & $76.2(494)$ & & $54.7(93)$ & $69.2(139)$ & $80.1(229)$ & & $45.2(89)$ & $66.2(186)$ & $73.2(265)$ & \\
\hline Any AMD & $50.4(185)$ & $32.6(157)$ & $23.8(154)$ & & $45.3(77)$ & $30.9(62)$ & $19.9(57)$ & & $54.8(108)$ & $33.8(95)$ & $26.8(97)$ & \\
\hline Early AMD & $36.2(133)$ & $26.8(129)$ & $19.9(129)$ & & $34.1(58)$ & $26.4(53)$ & $17.1(49)$ & & $38.1(75)$ & $27.1(76)$ & $22.1(80)$ & \\
\hline Late AMD & $14.2(52)$ & $5.8(28)$ & $3.9(25)$ & & $11.2(19)$ & $4.5(9)$ & $2.8(8)$ & & $16.8(33)$ & $6.8(19)$ & $4.7(17)$ & \\
\hline Incident $A M D$ at $A G E S-I^{* * *}$ & & & & 0.10 & & & & 0.12 & & & & 0.54 \\
\hline None & $62.0(49)$ & 84.3 (199) & $86.3(353)$ & & $64.5(20)$ & $79.0(79)$ & $91.1(163)$ & & $60.4(29)$ & $88.2(120)$ & $82.6(190)$ & \\
\hline Any AMD & $38.0(30)$ & $15.7(37)$ & $13.7(56)$ & & $35.5(11)$ & $21.0(21)$ & $8.9(16)$ & & $39.6(19)$ & $11.8(16)$ & $17.4(40)$ & \\
\hline
\end{tabular}

Resulfogare presented as mean (standard deviation) or percentage (count).

* Ca382 Zison of each characteristic, adjusting for age at AGES-I and sex, by birth cohort. 


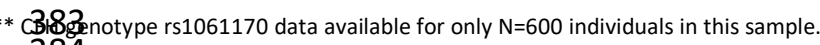

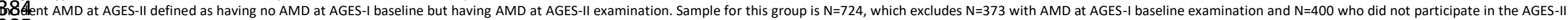
385 nation. 
Table 2. Mean Ponderal Index by Birth Cohort and Prevalent and Incident Age-Related Macular Degeneration in the AGESReykjavik Study

\begin{tabular}{|c|c|c|c|c|c|c|c|c|}
\hline \multirow[b]{2}{*}{ Birth Cohort } & \multirow[b]{2}{*}{$\begin{array}{l}\text { Prevalent AMD } \\
\text { at AGES-I or II }\end{array}$} & \multicolumn{3}{|c|}{ Mean Ponderal Index } & \multirow[b]{2}{*}{$\begin{array}{c}\text { Incident AMD } \\
\text { at AGES-II }\end{array}$} & \multicolumn{3}{|c|}{ Mean Ponderal Index } \\
\hline & & $\begin{array}{c}\text { All Individuals } \\
(\mathrm{N}=1497)\end{array}$ & $\begin{array}{c}\text { Men } \\
(\mathrm{N}=657)\end{array}$ & $\begin{array}{l}\text { Women } \\
(\mathrm{N}=840)\end{array}$ & & $\begin{array}{l}\text { All Individuals } \\
(\mathrm{N}=724)\end{array}$ & $\begin{array}{c}\text { Men } \\
(\mathrm{N}=310)\end{array}$ & $\begin{array}{l}\text { Women } \\
(\mathrm{N}=414)\end{array}$ \\
\hline \multirow[t]{2}{*}{$1914-1924$} & No & 26.6 (3.9) & $27.0(4.1)$ & $26.3(3.7)$ & No & 27.5 (4.9) & $28.4(4.6)$ & $26.9(5.0)$ \\
\hline & Yes & $26.7(3.5)$ & $26.3(3.1)$ & $26.9(3.7)$ & Yes & $25.6(3.4)$ & $26.0(3.2)$ & $25.4(3.6)$ \\
\hline \multirow[t]{2}{*}{$1925-1929$} & No & $26.7(3.3)$ & $26.9(3.5)$ & $26.5(3.1)$ & No & $26.4(3.3)$ & $26.6(3.6)$ & $26.3(3.1)$ \\
\hline & Yes & $26.5(3.5)$ & $26.5(3.4)$ & $26.5(3.6)$ & Yes & $26.9(3.2)$ & $27.8(3.4)$ & $25.9(2.8)$ \\
\hline \multirow[t]{2}{*}{$1930-1936$} & No & $24.9(2.7)$ & $24.8(2.7)$ & $25(2.6)$ & No & $24.9(2.6)$ & $24.6(2.6)$ & $25.1(2.6)$ \\
\hline & Yes & $24.9(2.8)$ & $24.8(2.6)$ & $25(2.9)$ & Yes & $24.6(2.7)$ & $24.3(2.8)$ & $24.7(2.7)$ \\
\hline \multirow[t]{4}{*}{ Total } & No & $25.8(3.3)$ & $25.9(3.5)$ & $25.7(3.1)$ & No & $25.6(3.2)$ & $25.5(3.4)$ & $25.7(3.1)$ \\
\hline & Yes & $26.1(3.4)$ & $25.9(3.2)$ & $26.2(3.5)$ & Yes & $25.6(3.2)$ & $26.2(3.4)$ & $25.2(3.0)$ \\
\hline & Early & $25.9(3.3)$ & $25.7(3.1)$ & $26.1(3.4)$ & & & & \\
\hline & Late & $26.6(3.8)$ & $26.8(3.5)$ & $26.5(3.9)$ & & & & \\
\hline
\end{tabular}

Ponderal Index $=\mathrm{kg} / \mathrm{m}^{3}$

Results are presented as means (standard deviation).

* Incident AMD at AGES-II defined as having no AMD at AGES-I baseline but having AMD at AGES-II examination. Incident AMD is only categorized as none or any AMD due to the extremely small number of cases of incident late AMD (e.g. N=4 with 1 case in 1914-1924 cohort, 2 cases in 1925 1929 cohort, and 1 case in 1930-1936 cohort). 
Table 3. Logistic Regression Models for Age-Related Macular Degeneration in Old Age by Body Size at Birth in Men and Women from the AGES-Reykjavik Study, Stratified by Birth Cohort, Odds Ratios and 95\% Confidence Intervals

\section{Prevalent AMD at \\ AGES-I or AGES-II}

Any AMD

Early AMD

\begin{tabular}{lrrrrrr}
\hline Birth Cohort & $1914-1924$ & $1925-1929$ & $1930-1936$ & $1914-1924$ & $1925-1929$ & $1930-1936$ \\
\hline
\end{tabular}

\section{All Individuals}

Birth Weight (kg)

$1.03(0.83,1.28) \quad 0.97(0.79,1.20)$

$0.94(0.77,1.13) \quad 1.02(0.80,1.30)$

$0.96(0.77,1.20) \quad 0.85(0.69,1.04)$

Birth Length $(\mathrm{cm})$

$1.08(0.87,1.34)$

$1.08(0.87,1.33)$

$0.93(0.77,1.12) \quad 1.09(0.86,1.39)$

$1.08(0.87,1.35)$

$0.86(0.70,1.06)$

Ponderal Index

$0.95(0.77,1.18)$

$0.92(0.75,1.13)$

$0.99(0.82,1.20)$

$0.91(0.72,1.16)$

$0.90(0.72,1.12) \quad 0.98(0.80,1.19)$

Men

Birth Weight (kg)

$0.89(0.65,1.24) \quad 0.93(0.67,1.30)$

$0.99(0.72,1.34) \quad 0.90(0.63,1.30)$

$0.92(0.65,1.30)$

$0.83(0.59,1.15)$

Birth Length $(\mathrm{cm})$

$1.10(0.78,1.54)$

$1.02(0.73,1.42)$

$0.94(0.69,1.29) \quad 1.12(0.77,1.63)$

$1.01(0.71,1.43)$

$0.86(0.62,1.21)$

Ponderal Index

$0.78(0.55,1.10)$

$0.89(0.64,1.23)$

$1.02(0.75,1.40)$

$0.75(0.51,1.11)$

$0.87(0.62,1.23)$

$0.89(0.64,1.25)$

\section{Women}

Birth Weight $(\mathrm{kg}) \quad 1.14(0.84,1.53) \quad 1.03(0.79,1.35) \quad 0.93(0.73,1.18) \quad 1.11(0.80,1.55) \quad 1.03(0.77,1.37) \quad 0.88(0.67,1.14)$

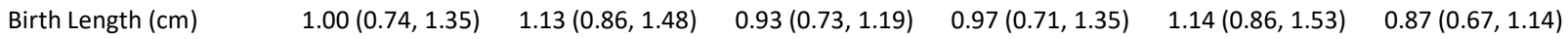

Results are presented as odds ratios and $95 \%$ confidence intervals.

Models are adjusted for sex (in combined analyses of all individuals), and education, age at AGES-I, BMI, smoking, alcohol consumption, prevalent coronary heart disease, diabetes, total cholesterol, and HDL cholesterol. 
Table 4. Logistic Regression Models for Incident Age-Related Macular Degeneration in Old Age by Body Size at Birth in Men and Women from the AGES-Reykjavik Study, Stratified by Birth Cohort, Odds Ratios and $95 \%$ Confidence Intervals

\begin{tabular}{|lccc|}
\hline Incident AMD at AGES-II & \multicolumn{3}{c|}{ Any AMD } \\
\hline Birth Cohort & $1914-1924$ & $1925-1929$ & $1930-1936$ \\
\hline All Individuals & & & \\
\hline Birth Weight $(\mathrm{kg})$ & $0.65(0.39,1.10)$ & $1.51(1.01,2.27)$ & $0.81(0.60,1.10)$ \\
Birth Length $(\mathrm{cm})$ & $1.14(0.68,1.92)$ & $1.39(0.94,2.05)$ & $0.91(0.67,1.22)$ \\
Ponderal Index & $0.50(0.28,0.92)$ & $1.13(0.77,1.64)$ & $0.87(0.64,1.18)$ \\
Men & & & \\
\hline Birth Weight $(\mathrm{kg})$ & $0.44(0.12,1.58)$ & $1.64(0.86,3.13)$ & $0.88(0.49,1.57)$ \\
Birth Length $(\mathrm{cm})$ & $0.86(0.17,4.36)$ & $1.07(0.60,1.91)$ & $0.95(0.54,1.66)$ \\
Ponderal Index & $0.20(0.02,1.77)$ & $1.61(0.86,3.01)$ & $0.89(0.47,1.67)$ \\
Women & & & \\
\hline Birth Weight $(\mathrm{kg})$ & $0.76(0.38,1.53)$ & $1.46(0.83,2.60)$ & $0.79(0.54,1.16)$ \\
Birth Length $(\mathrm{cm})$ & $1.11(0.54,2.25)$ & $1.70(0.96,3.01)$ & $0.90(0.63,1.30)$ \\
Ponderal Index & $0.62(0.28,1.35)$ & $0.83(0.45,1.55)$ & $0.86(0.60,1.24)$ \\
\hline
\end{tabular}

Results are presented as odds ratios and 95\% confidence intervals.

Models are adjusted for sex (in combined analyses of all individuals), and education, age at AGES-I, BMI, smoking, alcohol consumption, prevalent coronary heart disease, diabetes, total cholesterol and HDL cholesterol. 
405

406

407

408

409

410

411

412

413

414

415

\section{Figure Legends}

Figure 1A. Percentage of Individuals with Prevalent AMD by Ponderal Index and BMI at AGES-I Examination

Figure 1B. Percentage of Individuals with Incident AMD by Ponderal Index and BMI at AGES-I Examination

Figure 2.

Time of Global Events and Birth Years for Participants in Relevant Studies 
Figures

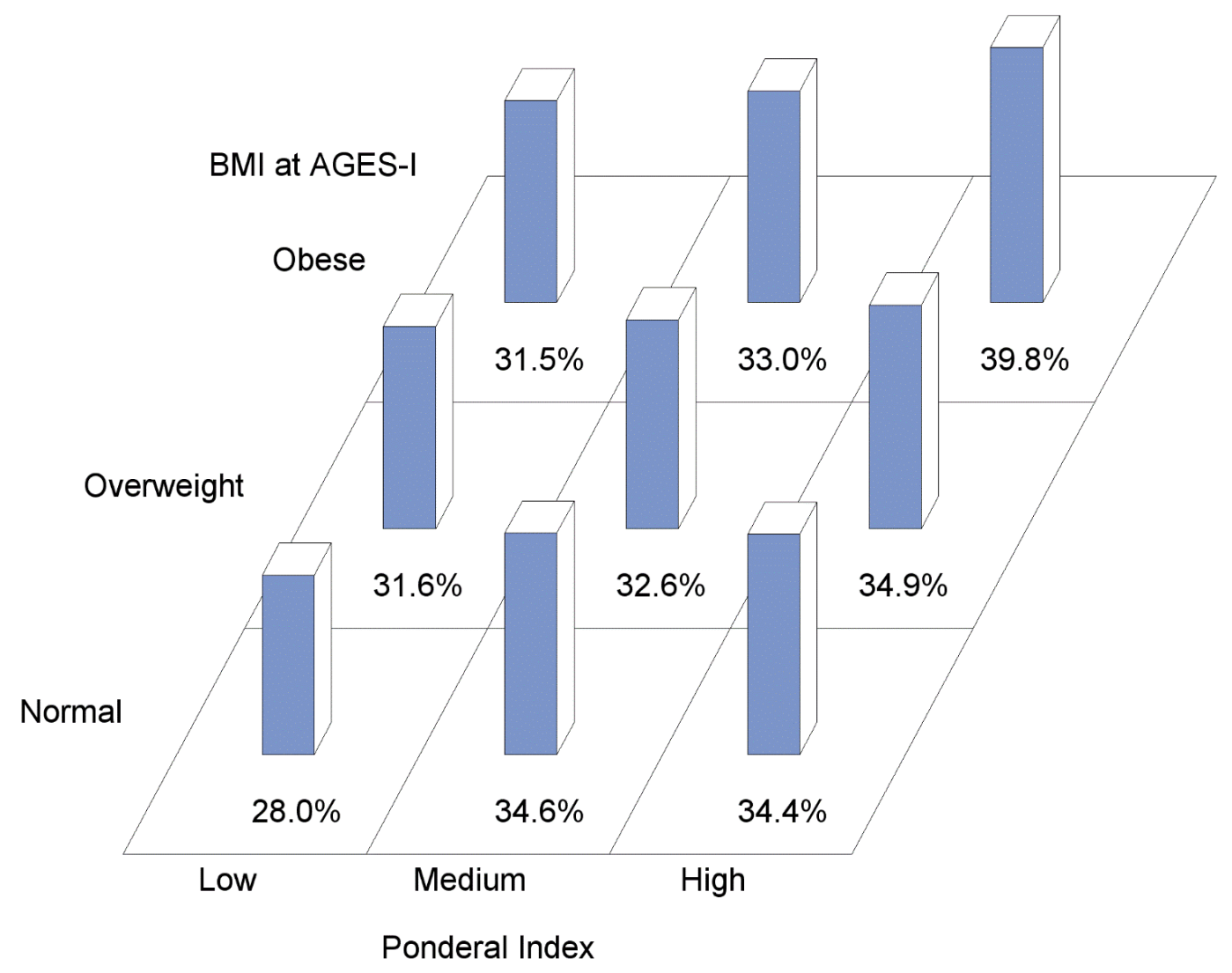

Figure $1 \mathrm{~A}$ 


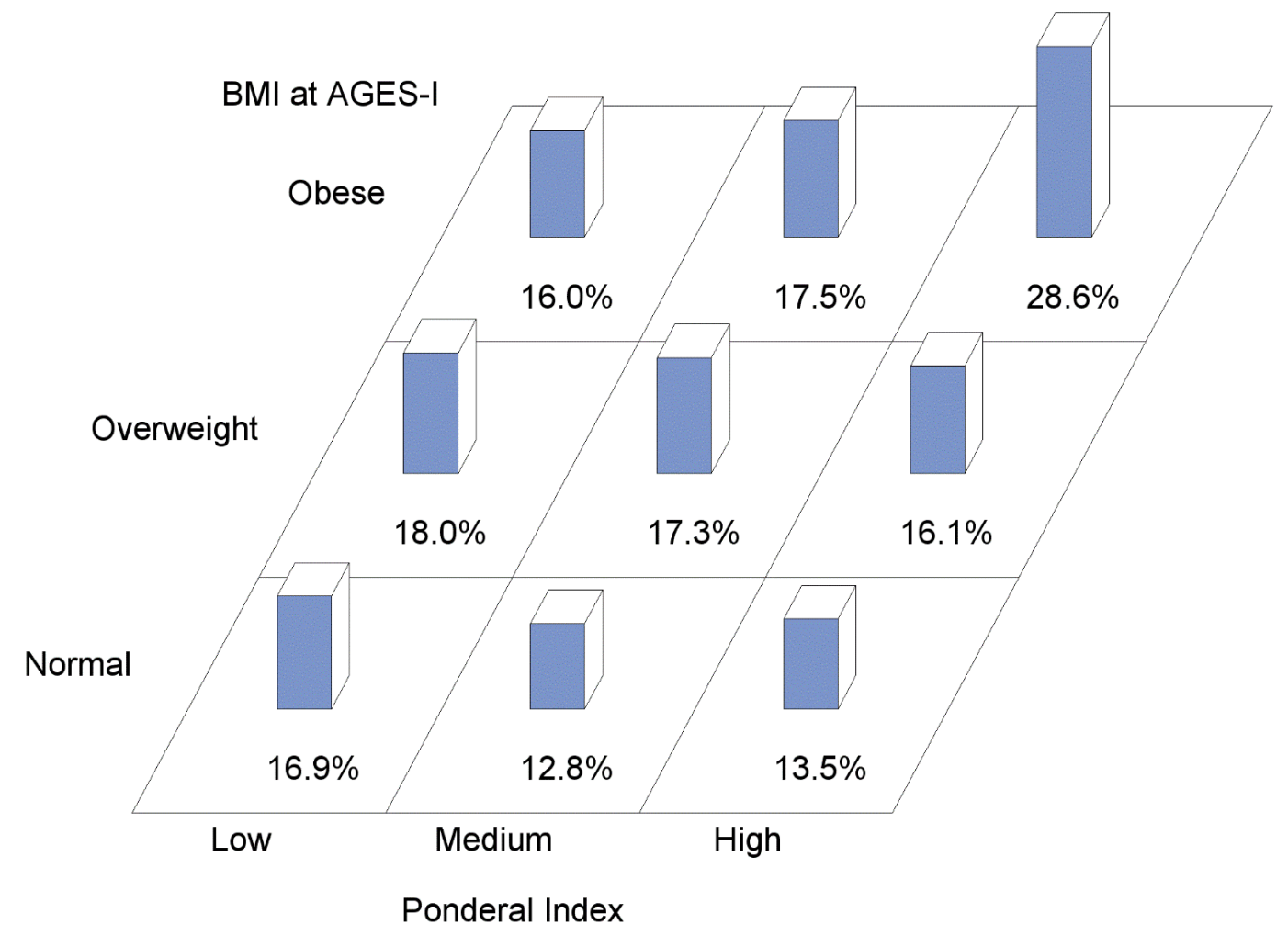

Figure $1 \mathrm{~B}$ 


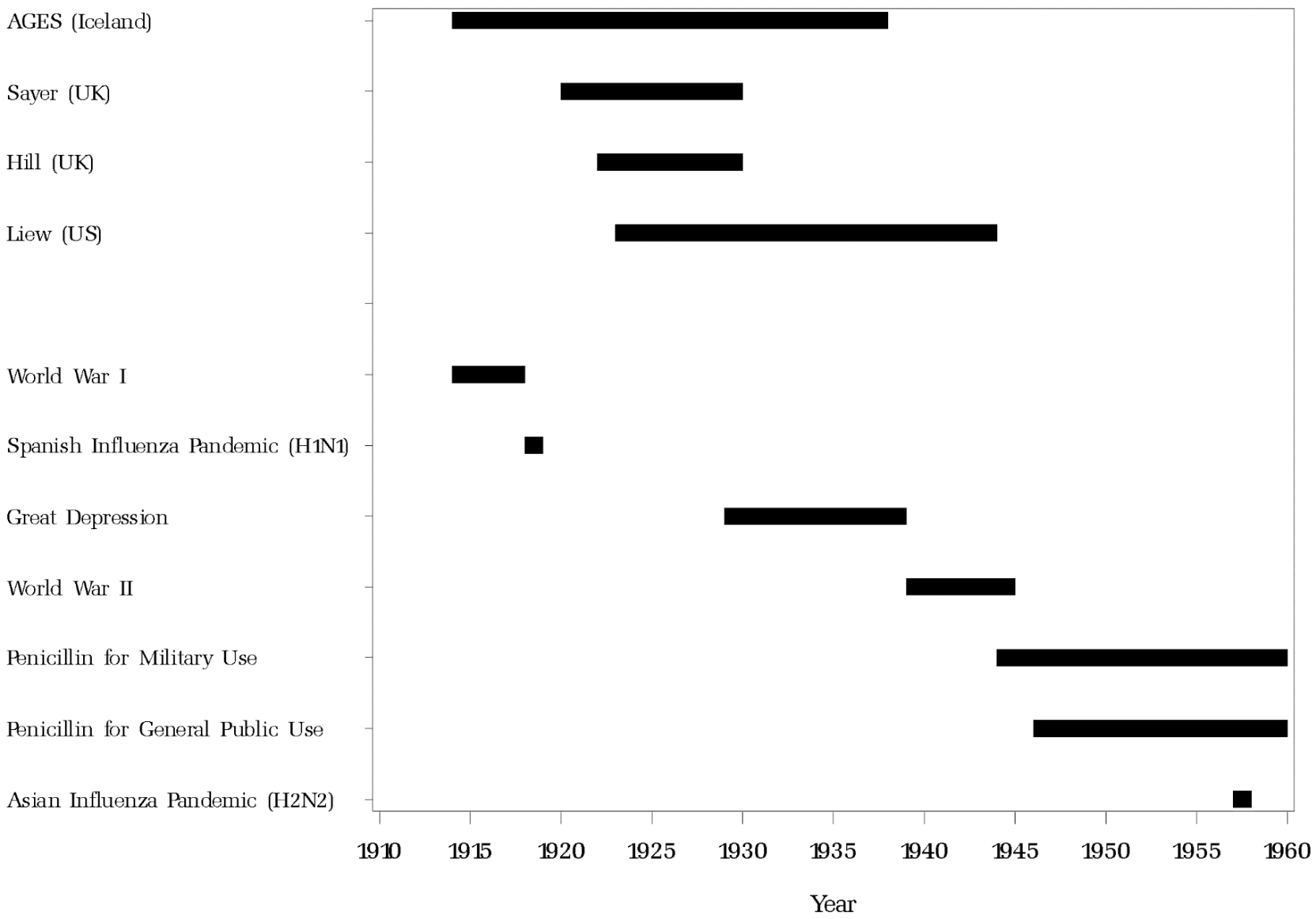

Figure 2 
Supplemental Table 1. Mortality and Age-Related Macular Degeneration for Individuals in the AGES-Reykjavik Study who have Birth Size data

\begin{tabular}{|c|c|c|c|c|c|c|c|c|c|c|}
\hline & \multicolumn{4}{|c|}{ All Individuals } & \multicolumn{3}{|c|}{ Men } & \multicolumn{3}{|c|}{ Women } \\
\hline & $\begin{array}{c}\text { Total }^{\mathrm{a}} \\
(\mathrm{N}=1691)\end{array}$ & $\begin{array}{c}1914-1924 \\
(\mathrm{~N}=454)\end{array}$ & $\begin{array}{c}1925-1929 \\
(\mathrm{~N}=529)\end{array}$ & $\begin{array}{c}1930-1936 \\
(\mathrm{~N}=708)\end{array}$ & $\begin{array}{c}1914-1924 \\
(\mathrm{~N}=209)\end{array}$ & $\begin{array}{c}1925-1929 \\
(\mathrm{~N}=221)\end{array}$ & $\begin{array}{c}1930-1936 \\
(\mathrm{~N}=314)\end{array}$ & $\begin{array}{c}1914-1924 \\
(\mathrm{~N}=245)\end{array}$ & $\begin{array}{c}1925-1929 \\
(\mathrm{~N}=308)\end{array}$ & $\begin{array}{c}1930-1936 \\
(\mathrm{~N}=394)\end{array}$ \\
\hline \multicolumn{11}{|l|}{ AGES-I AMD Status Available } \\
\hline Yes & $88.5(1497)$ & $80.8(367)$ & $91.1(482)$ & $91.5(648)$ & $81.3(170)$ & $91.0(201)$ & $91.1(286)$ & $80.4(197)$ & $91.2(281)$ & $91.9(362)$ \\
\hline No & $11.5(194)$ & $19.2(87)$ & $8.9(47)$ & $8.5(60)$ & $18.7(39)$ & $9.1(20)$ & $8.9(28)$ & $19.6(48)$ & $8.8(27)$ & $8.1(32)$ \\
\hline Died before Examination* & $77.8(151)$ & $95.4(83)$ & $76.6(36)$ & $53.3(32)$ & $100.0(39)$ & $70.0(14)$ & $64.3(18)$ & $91.7(44)$ & $81.5(22)$ & $43.8(14)$ \\
\hline \multirow[t]{3}{*}{ Missing for Other Reason* } & $22.2(43)$ & $4.6(4)$ & $23.4(11)$ & $46.7(28)$ & $0.0(0)$ & $30.0(6)$ & $35.7(10)$ & $8.3(4)$ & $18.5(5)$ & $56.2(18)$ \\
\hline & & \multicolumn{3}{|c|}{ All Individuals } & \multicolumn{3}{|c|}{ Men } & \multicolumn{3}{|c|}{ Women } \\
\hline & $\begin{array}{c}\text { Total }^{\mathrm{b}} \\
(\mathrm{N}=1497)\end{array}$ & $\begin{array}{c}1914-1924 \\
(\mathrm{~N}=367)\end{array}$ & $\begin{array}{c}1925-1929 \\
(\mathrm{~N}=482)\end{array}$ & $\begin{array}{c}1930-1936 \\
(\mathrm{~N}=648)\end{array}$ & $\begin{array}{c}1914-1924 \\
(N=170)\end{array}$ & $\begin{array}{c}1925-1929 \\
(\mathrm{~N}=201)\end{array}$ & $\begin{array}{c}1930-1936 \\
(\mathrm{~N}=286)\end{array}$ & $\begin{array}{c}1914-1924 \\
(\mathrm{~N}=197)\end{array}$ & $\begin{array}{c}1925-1929 \\
(\mathrm{~N}=281)\end{array}$ & $\begin{array}{c}1930-1936 \\
(\mathrm{~N}=362)\end{array}$ \\
\hline \multicolumn{11}{|c|}{ AGES-II AMD Status Available } \\
\hline Yes & $61.3(917)$ & $37.1(136)$ & $62.2(300)$ & $74.2(481)$ & $29.4(50)$ & $61.7(124)$ & $73.8(211)$ & $43.6(86)$ & $62.6(176)$ & $74.6(270)$ \\
\hline No & $38.7(580)$ & $62.9(231)$ & $37.8(182)$ & $25.8(167)$ & $70.6(120)$ & $38.3(77)$ & $26.2(75)$ & $56.4(111)$ & $37.4(105)$ & $25.4(92)$ \\
\hline Died before Examination* & $36.7(213)$ & $36.8(85)$ & $35.2(64)$ & $38.3(64)$ & $38.3(46)$ & $44.2(34)$ & $49.3(37)$ & 35.1 (39) & $28.6(30)$ & $29.3(27)$ \\
\hline Missing for Other Reason* & $63.3(367)$ & $63.2(146)$ & $64.8(118)$ & $61.7(103)$ & $61.7(74)$ & $55.8(43)$ & $50.7(38)$ & $64.9(72)$ & $71.4(75)$ & $70.7(65)$ \\
\hline
\end{tabular}

* Percentage denominator is the number of individuals who do not have available AMD status (e.g. 'No').

a Sample of individuals with birth size data who participated in the AGES-Reykjavik study.

${ }^{b}$ Sample of individuals with birth size data and AGES-I AMD data who participated in the AGES-Reykjavik study. 